\title{
EDUCACIÓN PARA LA TRANSFORMACIÓN \\ La epistemología del intersujeto
}

\author{
Marcelo Rodríguez
}

No es posible encarar la educación a no ser como un quehacer humano. Quehacer, por tanto, que se da en el tiempo y en el espacio, entre los hombres, unos con otros. (...) su vocación ontológica, que él debe existenciar, es la de sujeto que opera y transforma el mundo.

Paulo Freire

Las cuestiones referidas a la "Educación" tienen una larga data de discusión e institucionalización de diversos discursos que no pueden ser aislados de las condiciones ontológicas, epistemológicas, metodológicas, éticas y sociopolíticas desde donde esas referencias se enuncian. El desarrollo del pensamiento occidental estructura nuestras cotidianidades y formas de interrelación social. Estas formas integran los procesos de recursividad en cada ser humano, y se constituyen en función del conjunto de roles vinculantes desde, para y con la cultura.

Si existe un consenso global en torno a mejorar las condiciones de vida de la humanidad, es indiscutible que una de las vías "estratégicas" es el dispositivo de la educación. La correlación entre desarrollo y educación es evidente.

\footnotetext{
* Licenciado en Psicología con mención en Psicología Social de la Universidad de Valparaíso, Chile. Docente de la Universidad Politécnica Salesiana - Quito.
} 
La pregunta: ¿qué es la educación? no es suficiente para describir supuestos elementos de "subjetividad u objetividad" en el plano de las relaciones-vinculaciones y espacios de administración de poder en educación, sino más bien se centra el tema en las "condiciones de educabilidad"; ¿para qué educar?, ¿quiénes significan y operacionalizan esos significados educativos?, ¿cuál es la concepción epistémica y de sujeto que se sustenta?, y más aún, ¿qué es lo que se pretende desarrollar e institucionalizar para avanzar en justicia social y calidad de vida de los/as ciudadanos/as?

La nueva Ley de Educación del Ecuador es expresa en este sentido y sostiene que: "El nuevo modelo que lleva adelante la revolución del sistema educativo es inclusivo y prepara ciudadanos solidarios para el buen vivir, con respeto por la naturaleza y con conciencia ecológica, con los conocimientos suficientes para generar, no solo una masa crítica que discuta con solvencia los problemas socio-económicos del país y del mundo, sino que además tenga las capacidades para continuar su preparación académica y/o incorporarse de manera inmediata a los procesos productivos y de desarrollo local, regional y/o nacional".

A lo largo de la historia, se han venido ensayando 18 programas de reformas curriculares. Los objetivos de la última responden a la universalización de la educación pre-escolar, escolaridad mínima de 10 años, formación de estudiantes capaces de comprender para transformar, incremento de partidas docentes, preparación y evaluación del docente, flexibilidad en el contenido y en la metodología (Velásquez y Saltos, 2006). En efecto, el centro de la discusión política intenta afrontar las enormes brechas que reproducen las condiciones de desigualdad y de vulneración del derecho a una educación de calidad. 
Sólo para situar el contexto educativo, la Fundación de Investigación y Promoción Social "José Peralta" (2006), en su versión decimocuarta, indica que en el ciclo primario, el índice de deserción escolar es de 11\% en el área urbana y $53 \%$ en el área rural. 1 de cada 5 niños abandona la escuela en el cuarto grado y cerca del $40 \%$ no concluye la escuela. En la educación secundaria, 4 de cada 10 personas mayores de edad habían concluido sus estudios secundarios.

En este contexto, el presente artículo intenta ampliar la discusión de los paradigmas de la psicoeducación, considerando aspectos éticos y políticos, en nuestro entorno latinoamericano. Para esto, hacemos un recorrido por algunos aspectos filosóficos y epistemológicos con el propósito de aproximarnos a un enfoque que va más allá de las nociones de subjetividad. Nos compromete un análisis de sentidos y significados en que, el lenguaje, utilizado en el contexto de la educación, no debe descontextualizarse de los marcos de relaciones de poder desde donde se construye la realidad, las prácticas educativas y por ende, la ciudadanía.

\section{Educación y contexto}

Como primera aproximación, vemos que la "educación" es inherente a la condición y organización de la humanidad en sus diversas expresiones socio-históricas. Si nos remitimos a las fuentes de significado de este término, a su etimología, tenemos que, educación proviene del latín "educare" que significa criar, alimentar, cuidar, con su acepción "educar" e "instruir".

El sistema básico de educación que se asentó en nuestra cultura, se remonta a la Grecia del siglo V a.C. En este período, los pedagogos, es decir, los "conductores de 
niños", eran esclavos que dirigían a los infantes a las escuelas públicas para iniciar su proceso de aprendizaje. Aprendizaje proviene del latín apprehendere que significa: "apoderarse de algo", "aprehender", "coger" (Santiago, 1997). En efecto, la educación se entiende como el proceso de criar, enseñar y adoctrinar a niños y jóvenes, a quienes se les transmite un "conocimiento" y "valores" que se experimentan desde los primeros años de vida en el grupo familiar, luego en la escuela y/o universidad y durante el periodo de vida.

En el concierto latinoamericano, los constantes procesos de transformación propios de la postmodernidad, y en particular de los cambios sociales que en el país se están dando, permiten preguntarse por una "educación transformadora”. Sin embargo, la crítica política refiere a que los dispositivos institucionales, conjuntamente con su quehacer y sus discursos, han estado orientados esencialmente al mantenimiento del "estatus quo". Es la concepción del moldeamiento del comportamiento humano basado en una cierta estabilidad del sistema social que tiende a su autodeterminación. Se ha co-construido en base a los discursos, es decir, al conjunto de prácticas lingüísticas que mantienen y promueven cierto tipo de relaciones sociales, a sujetos "sujetados" al sistema imperante, de modo que, las nuevas generaciones aumentan su probabilidad de éxito socioeconómico, en tanto adquieren las habilidades para integrarse a la sociedad de consumo. En efecto, deben emprenderse a desarrollar "competencias" para enfrentar la vida y responder a formas de relaciones socialmente aceptadas y valoradas. Esta noción muy asentada, y a la que podemos denominar "verdad adultocéntrica", se muestra insuficiente a la hora de preguntarse por una educación que propicia la reflexión-acción, con un compromiso por "lo social" y por los procesos de organi- 
zación, desideologización y desarrollo de la ciudadanía como contrapartida a los procesos de naturalización del tejido social. A continuación nos remitiremos a abordar los aspectos históricos y filosóficos para situar la noción de subjetividad.

\section{Filosofía, educación y subjetividad}

Posterior a las cuestiones de la filosofía cosmológica ocupada de la "unidad" de la "sintonía" del universo, surgen las preocupaciones por el hombre. En esta época se producen importantes cambios, a saber: aparecimiento de nuevas actividades públicas, crecimiento de las ciudades, mayor democratización con la vida en las asambleas, entre otras; desde donde sale, entonces, la necesidad de comprensión de la vida humana, en términos de las relaciones entre los hombre y las relaciones con Dios. Había, por tanto, que preparar teórica y prácticamente a las nuevas generaciones para orientarse en el mundo, para discernir lo bueno de lo malo. Quienes se ocuparían de esta tarea ciudadana eran los llamados "maestros de sabiduría”, los sofistas (Giannini, 1981).

Sócrates hizo del diálogo una de las más importantes actividades de su existencia. Según su método, la mayéutica, debía producirse un reconocimiento de la ignorancia para que la verdad "alumbrara". Como contrapartida, el grupo de los sofistas, con una dedicación profunda por las ciencias humanas y en especial por la educación, llegan a declarar que todo es relativo, que no hay una verdad común para todos y que lo bello, lo feo, lo justo, lo injusto, lo bueno o lo malo, depende totalmente de nuestra condición, de nuestra cultura, de la ciudad y de los tiempos que vivimos. El relativismo extremo sofista está representado por el "subjetivismo", en donde la ver- 
dad es lo que cada individuo considera verdadero, según su propio modo de sentir y pensar. A este respecto es representativa la frase de Protágoras: el Hombre es la medida de todas las cosas. Para Sócrates, la verdad es la captación de algo común que existe con independencia de cada uno de nosotros. El bien individual es inseparable del bien general, la subjetividad, en consecuencia, debe reconocer y dejarse determinar por la realidad objetiva de lo común.

En el devenir de la historia, las discusiones y posiciones en torno a la objetividad-subjetividad han configurado diversas corrientes de teorías filosóficas sobre la verdad y realidad y el estatus ontológico y epistemológico del saber científico. En la actualidad, en el ámbito educativo, hay una especie de descrédito de la reflexión filosófica que se relaciona con la hegemonía del pensamiento positivo, derivado del empirismo inglés. Lo que se "sabe" es aquello que es observable, cuantificable y manipulable por el conjunto de nuestros sentidos. La filosofía racional de la educación tiene como fin ordenar los actos del que enseña una determinada técnica, hasta conseguir que el aprendiz adquiera "suficiente destreza" como para valerse por sí mismo.

La educación es un concepto fundamentado en los diversos sentidos de virtud, la que, de cierto modo, responde a la condiciones de eduacabilidad. Martínez (2009) lo define como la ordenación a satisfacer una determinada necesidad, la de llegar a ser capaz de obrar virtuosamente. Por ello, no se pretende en este caso la felicidad, sino una mayoría de edad moral en la que estar bien dispuesto para ir a la zaga de aquélla. No obstante lo anterior, la virtud es una instancia definida y significativa para un grupo y un modo de ser en el mundo.

Las condiciones de educabilidad se entienden 
como el conjunto de recursos, aptitudes o predisposiciones que permiten que un niño o adolescente pueda asistir exitosamente a la escuela. Esta noción invita a analizar cuáles son las condiciones sociales que hacen posible que todos los niños/as y adolescentes accedan a esos recursos. La premisa es que todo niño/a nace potencialmente educable, pero el contexto social latinoamericano opera, en muchos casos, como obstáculo que impide el desarrollo de esta potencialidad.

\section{Psicoeducación y su trasfondo pluriparadigmático}

Los avances en educación se inscriben en los progresos de las ciencias de la educación, de modo que, toda ciencia se estructura en un programa de investigación, es decir, construye una problemática que se sustenta a la vez de los fundamentos epistemológicos, con un conjunto de supuestos o constructos teóricos, un encuadre metodológico y nociones de aplicabilidad de ese saber desarrollado. El concepto de paradigma más conocido es el acuñado y desarrollado por Khun en su obra La Estructura de las Revoluciones Científicas. El centro de la discusión remite al "progreso de la ciencia". Cabe la pregunta sobre los factores que inciden en el desarrollo de la ciencia de la educación ¿desde dónde progresa la ciencia de la educación? Las posibilidades de respuesta son básicamente dos. Por un lado, son los factores internos del quehacer científico dado por un programa netamente racionalista ${ }^{1} \mathrm{y}$, por otro, se progresaría en función de factores externos (sociológicos y psicológicos), y no bajo un continuo de acumulación de éxitos o logros científicos, sino como un "contexto de descubrimiento" contenido en un espaciotiempo- socio-histórico. 
Para el caso de la psicoeducación, se observa que existe una convivencia de corpus teóricos-metodológicos que se institucionalizan según el grado de hegemonía que puedan conseguir en la comunidad científica. El grado de hegemonía que estamos vivenciando responde al antiguo sistema de instrucción, vale decir, el saber se trasvasija en quienes no saben y éstos deben aprehender el conocimiento.

Estas nociones de paradigmas son aplicables al desarrollo de las ciencias de la educación, las cuales se han nutrido de la psicología general y su aplicabilidad al ámbito de la educación.

Según Hernández (1998), las tradiciones que fueron configurando una identidad a la psicología educativa (a principios del siglo XX), comprenden el estudio de las diferencias individuales, enraizado en el naciente enfoque psicométrico; los estudios de la psicología evolutiva o psicología del niño y los trabajos sobre la psicología del aprendizaje.

Ahora bien, en este corto período histórico de desarrollo, vemos que la psicología educativa se concibe como una disciplina pluriparadigmática, cada una con su concepción epistémica desde donde fundamenta su producción teórico-práctica.

En el siguiente apartado, revisaremos los principales fundamentos epistemológicos de cada uno de los paradigmas psicoeducativos, para adentrarnos en el enfoque reflexivo de intersubjetividad y su relación con el espacio educativo.

\section{Marco epistémico del trasfondo pluriparadigmático}

Es sabido que, al generar cualquier afirmación sobre la realidad, cabe la pregunta primigenia del “ ¿cómo 
es que conocemos?". Al respecto, cada comunidad científica que adhiere un paradigma, sostiene su propia sentencia epistémica.

Así, la tradición filosófica del empirismo inglés, que fundamenta el programa asociacionista del enfoque conductual, afirma que el conocimiento sería una copia isomórfica de la realidad. Ésta se configura por medio de mecanismos asociativos de sensaciones, ideas y relaciones entre éstas. El sujeto congnoscente, en este caso un estudiante, adquiere un rol pasivo, siendo el ambiente el que determina el modo de comportamiento de aquel. Se reduce la actividad educativa a las influencias externas sin considerar ninguna organización estructural, por lo que los conocimientos del sujeto son la suma de asociaciones entre estímulos y respuestas.

Por otra parte, el paradigma humanista tiene sus fundamentos en las líneas de pensamiento de la fenomenología y el existencialismo. Esta corriente aparece como una tercera vía alternativa al predominio de las determinantes ambientales propias del conductismo y del enfoque analítico de los problemas del inconsciente y su sustrato innatista. Se caracteriza por una visión de los procesos integrales de las personas en el contexto social, de modo que es la persona la principal fuente del desarrollo integral.

La concepción del ser humano de acuerdo al existencialismo responde a un ser en libertad, en que cada uno de nosotros forja su propio destino. Según Jean-Paul Sartre, cada uno de nosotros es producto de sus "propias elecciones” (Hernández, 1998). Para la fenomenología, los seres humanos conducen sus vidas a través de sus propias percepciones subjetivas respondiendo al ambiente tal y como lo perciben y comprenden (Hernández, 1991).

Cada persona tendería de forma natural a su autorrealización en consistencia con un ambiente propi- 
cio para ello, es decir, no amenazante y empático. La institución educativa debiese estructurarse de acuerdo a la idea de ayudar a los estudiantes a decidir sobre lo que son y qué quieren ser, generando las condiciones para que cada individuo desarrolle sus capacidades de aprendizaje basados en la relación comprensiva. Rogers plantea una "educación democrática centrada en la persona", a partir de la cual, la educación tiene por objeto crear estudiantes con iniciativa y autodeterminación. Se confiere, en efecI02 to, la responsabilidad de la educación al alumno (Hernández, 1998).

El paradigma cognitivo ha influenciado notablemente el campo de la psico-educación desde la década de los cincuenta en adelante. Según Gardner (1988), el núcleo de las teorías cognitivas se centraría en su concepción representacionista del conocimiento y su proposición de la metáfora computacional para explicar el funcionamiento de la mente. Desde estos supuestos, el sistema cognitivo funcionaría a través de cualquier dispositivo capaz de manipular símbolos, no requiriendo actuar sobre su dimensión semántica, sino simplemente con sus atributos formales o dimensión sintáctica. El sistema funciona correctamente cuando logra generar representaciones semánticas adecuadas en relación a algún aspecto del "mundo real", y cuando el procesamiento de la información conduce a una adecuada solución a los problemas presentados al sistema (Sandoval, 2002).

Este paradigma remite la mirada de su análisis exclusivamente en las variables del individuo y de la tarea o situación ambiental a la cual está enfrentado el sujeto, obviando las condiciones culturales y materiales de las cuales forma parte el individuo (Sandoval, 2002).

En términos epistemológicos, el sujeto cognoscente elabora sus representaciones de modo esencialmente individual. Dichas representaciones mentales determi- 
nan las formas de actividad que realiza el sujeto (Hernández, 1998). La noción del estudiante, en consecuencia, sería la de un sujeto como agente activo, con una organización interna a partir de la reelaboración constante de su relación de intercambio con el exterior, de modo tal que interpreta y configura nuevos formas significativas de la realidad. Se espera que la educación se oriente hacia los aprendizajes significativos, el desarrollo de habilidades y competencias.

Por otra parte, los primeros trabajos que configuraron el paradigma del constructivismo, corresponden a la lógica y al pensamiento verbal de los niños de Piaget. Este pensador suizo, de la escuela de Ginebra, se centra en observar los procesos de transformación del conocimiento desde una perspectiva diacrónica, no desde el estado final del conocimiento. Según su epistemología genética existiría un interaccionismo entre la relación sujeto-objeto, un espacio de interdependencia. El sujeto, para conocer, activa una serie de operaciones que definen y estructuran al objeto y, a la vez, el objeto incide en el sujeto de modo tal que se producen cambios en las representaciones que el sujeto construye del objeto (Hernández, 1998).

Según Piaget, "el principal objetivo de la educación es crear hombres que sean capaces de hacer cosas nuevas, no necesariamente repetir lo que han hecho otras generaciones: hombres que sean creativos, inventivos y descubridores. El segundo objetivo de la educación es formar mentes que puedan criticar, que puedan verificar y no aceptar todo lo que se les ofrezca" (1964, citado en Hernández, 1998: 192). Desde este prisma, el estudiante es un constructor activo de su conocimiento y reconstructor de los contenidos educativos en su contexto. Se espera generar, en el devenir educativo, un sentimiento de confianza del estudiante en sus propias producciones, 
críticas, ideas, propuestas, etcétera para construirse como un ser crítico ante la realidad que se le impone institucionalmente, con autonomía y desde un reflexionar sobre sus errores.

El enfoque sociocultural configura el paradigma propuesto por Vigotsky. Él reaccionó ante el estudio fragmentado de los procesos psicológicos superiores de su época, que estarían directamente influenciados por los procesos de evolución histórica y social. Las influencias del pensamiento de Hegel y del materialismo dialéctico de Marx y Engels fueron claras. El enfoque epistémico abordado por Vigotsky, introduce la noción dialéctica al Interaccionismo de la relación sujeto-objeto. Cole (1992, citado en Hernández, 1998) señala que esta relación, esencialmente bipolar en otros paradigmas, se convierte en un triángulo abierto a los procesos de influencia de un grupo sociocultural determinado, en el que los tres vértices representan al sujeto, el objeto y los artefactos o instrumentos socioculturales.

Las relaciones adquieren, entonces, un componente de "mediación", en donde el medio sociocultural influye sobre la realidad del sujeto, quien reconstruye activamente esta influencia. La práctica social o educativa de los sujetos estaría mediada por instrumentos de naturaleza sociocultural, que en función de las interacciones sociales, el sujeto reconstruiría el espacio sociocultural en el que experimenta su vida. Para Vigotsky la educación debiera estructurarse y dirigirse para desarrollar las funciones psicológicas superiores. Las metas educativas se constituirían en función de lo que la cultura considere como valioso, entendido el estudiante como un ser social, producto y protagonista de las diversas interacciones socio-culturales de las que es parte (Hernández, 1998). A su vez, es la interacción con los maestros, do- 
centes, estudiantes, etcétera lo que adquiere preponderancia para el desarrollo psicológico. Es el maestro el que se concibe como un agente cultural que media entre el saber sociocultural y los procesos de apropiación de los estudiantes. A este respecto, el concepto de Zona de Desarrollo próximo $(Z D P)$ es nuclear en el paradigma sociocultural. Vigotsky lo define como:

"La distancia entre el nivel real de desarrollo, determinada por la capacidad de resolver independientemente un problema, y el nivel de desarrollo potencial, determinado a través de la resolución de un problema bajo la guía de un adulto o en colaboración con otro compañero más capaz"

Hernández, 1998

Este concepto supone concebir el aprendizaje como un proceso de naturaleza social, a través del cual se vinculan los instrumentos y signos culturales.

Ahora bien, hemos hecho un sucinto recorrido por los fundamentos epistemológicos de los paradigmas que han influenciado los ámbitos de las ciencias de la educación. Ahora nos centraremos en los referentes y aportes de la psicología social socioconstruccionista para incluir nuevas concepciones analíticas que puedan permitir incorporar otros temas a la hora de pensarse una educación para la transformación social.

\section{Enfoque de intersubjetividad}

Las reflexiones sobre la naturaleza social del hombre han sido discutidas y abordadas a lo largo de la historia del pensamiento. Analizar los aportes y posible apertura de la discusión paradigmática psicoeducativa, nos remite a contextualizar algunos antecedentes de la 
perspectiva psicosocial. En efecto, hay que señalar a Aristóteles y Platón como dos de los pensadores que se ocupan de temas que hoy se consideran propios de la psicología social, de modo que la concepción ontológica del ser humano se diferencia en cada uno de los autores. "El hombre es un animal social" es la conocida sentencia de Aristóteles pare afirmar la naturaleza humana. En Platón encontramos una visión utilitarista del ser humano, en el sentido de que la formación de los grupos sociales se realizaría con el fin de satisfacer las necesidades del hombre, es decir los Estados son lo que los hombres son (Sabucedo, 1997). La discusión histórica se sitúa en la relación individuo-sociedad. Así como Platón otorga al Estado un papel determinante en cuanto permitía la socialización de los ciudadanos, Aristóteles defendía que el propio ser humano es por naturaleza social. En este sentido, para la concepción platónica, primarían las estructuras sociales mientras que para los aristotélicos el individuo será el principal punto de referencia.

Nutridos son los cuestionamientos en la época del Renacimiento y la Ilustración. De hecho, en este periodo se inicia una nueva forma de entender el mundo, es una reacción contra el espíritu teológico y autoritario de la Edad Media. Se intenta combatir el poder de la aristocracia y el dogma de las ideas religiosas. Surge la creencia en el poder de la razón y del intelecto humano para desentrañar los misterios de la naturaleza. Sabucedo (1997) afirma que la apelación a lo mágico-mítico y a la divinidad para explicar y justificar tanto las situaciones de opresión y desigualdad social, como los orígenes del poder y la autoridad, deja paso a un análisis racional de estas cuestiones. La realidad social ya no es inmodificable, sino que se puede transformar y mejorar.

La clásica discusión individuo-sociedad está fundamentada en una relación o lectura binaria, que, por 
lo demás, configuró una psicología social psicológica y una sociológica. Ésta supone la separación del sujeto y del objeto que son dados y definidos independientemente el uno del otro.

El psicologismo es una de las tendencias culturales más acentuadas en nuestros tiempos. Y podríamos definir el psicologismo como aquella comprensión de los fenómenos y procesos sociales que los reduce y explica como la simple adición de procesos puramente psicológicos (Martín-Baró, 1988). De hecho, Ricardo Zúñiga (citado en Martín-Baró, 1988) señala tres errores al utilizar un análisis "centrado en la persona" en el contexto de la psicología social, a saber: 1) la transformación del objeto de estudio. Al redefinir un problema o proceso social con variables psicológicas, se produce una alteración esencial en el objeto de análisis. No es lo mismo hablar de cambio social que de cambio de actitudes, de ideología que de motivación; 2) un análisis centrado en la persona produce un sutil pero significativo efecto de descontextualización y atemporalización que encubre el juego de las fuerzas sociales en un momento histórico específico; y 3) el análisis centrado en la persona tiende a atribuir la causalidad de los hechos a los individuos y sus características que en el fondo es consecuencia de la ideología política liberal-burguesa.

Ahora bien, retomando nuestro objeto de análisis en cuanto a la configuración de la realidad, se considera que el mismo sentido común constituye el mundo en dos partes, en dos realidades. Por ejemplo, la realidad subjetiva y objetiva, la realidad de lo consciente y de lo inconsciente, la ciencia y la creencia, la educación formal e informal. Estas realidades pueden ser antagónicas o complementarias.

El argumento que intenta ampliar la discusión paradigmática es el concepto de la "intersubjetividad" 
sustentado en el enfoque psicosocial propuesto por la psicología social crítica. Se pasaría de una visión binaria de la realidad, según Moscovici, a una visión "Psicosocial" o ternaria de los hechos y las relaciones.

Las posibilidades analíticas de la educación se amplían al concebir que "la estructura de la vida es una retícula trinodal, donde, junto al nudo de la realidad subjetiva individual y al de la realidad objetiva institucional, aparece una realidad intersubjetiva, $y$, a su vez, la intersubjetividad constituye una realidad triádica" (Fernández, 1994). Esta "realidad" no está ni en los individuos (educandos) ni en las instituciones educativas, sino "entre" estas dos instancias existenciales que se co-construyen. Esta tercera naturaleza se materializa en el contexto de interacción-comunicación y del lenguaje. A diferencia de la realidad subjetiva u objetiva, la realidad de la intersubjetividad ejerce el papel de mediadora en la construcción de símbolos, significados y sentidos de la educación.

Si nos preguntamos por el nombre, símbolo o lenguaje "educación", vemos que esta realidad "real" no aparece como una realidad dura. Educación es aplicable en tanto hay seres humanos que se "educan". Son las condiciones de intersubjetividad las que determinan cuándo educación es: educación de calidad, educación transformadora, educación interculturalidad bilingüe, educación popular, educomunicación, etcétera.

En consecuencia, la terceridad (palabra de Pierce) aporta el sentido en el que el símbolo tendrá significado; es decir, la relación entre a y b está mediada por una interpretación c. Esta relación diádica se encarna en la historia de un sentido interpretante que no puede ser exactamente arbitraria, porque es heredero de alguna tradición. (Fernández, 1994).

En esta misma línea argumentativa se inscribe el programa socioconstruccionista (derivado de la crisis de 
la psicología social ${ }^{2}$, que considera al lenguaje como unidad de análisis de los procesos sociales y humano. Es más, este "giro lingüístico" concibe al lenguaje como el mundo en sí mismo.

En este sentido, Gergen $(1996)^{3}$ asevera que:

- "Los términos con los que damos cuenta del mundo y de nosotros mismos no están dictados por los objetos estipulados de este tipo de exposiciones" (...).

- "Los términos y las formas por medio de los que conseguimos la comprensión del mundo y de nosotros mismos son artefactos sociales, productos de intercambios situados histórica y culturalmente y que se dan entre personas" (...).

- "El grado en el que un dar cuenta del mundo o del yo se sostiene a través del tiempo, no depende de la validez objetiva de la exposición, sino de las vicisitudes del proceso social" (...).

- "El significado del lenguaje en los asuntos humanos se deriva del modo como funciona dentro de pautas de relación".

EL socioconstruccionismo sostiene que, lo que tomamos como objetos naturales de nuestras vidas cotidianas, no son sino objetivaciones que resultan de nuestras convenciones y de nuestras prácticas lingüísticas. En palabras de Ibáñez (citado en Sandoval, 2002), "Lo que aquí se está afirmando es que la realidad no existe con independencia de nuestro modo de acceso a la misma (...) $\mathrm{Ni}$ la distancia, ni el fuego, ni el árbol, ni el cáncer, ni la paranoia existen en la realidad con independencia de nosotros, de nuestra conformación como seres humanos y como seres sociales".

Ahora bien, "la verdad adultocéntrica" sobre la educación es sólo un valor de uso, que no es común para 
todos los habitantes de este planeta, sino que cambia con la historia y la cultura, así como con el enunciado y el acto de enunciación, de modo que, tal verdad es un consenso producido en libertad, pero enmarcado por una red de prácticas de poder e instituciones coactivas, que opera en un determinado espacio y situación. De hecho, Johnson (1972) considera que desde el punto de vista de la psicología social, la educación se lleva a cabo en un medio social organizado y principalmente a través de procesos interpersonales. Se considera, por tanto, que los procesos interpersonales se hallan afectados por la organización o institución en cuyo seno se producen" 4 .

De acuerdo con un enfoque dialéctico, la educación debería examinarse como un proceso interpersonal al interior de una determinada estructura sociopolítica. En este sentido, Martín-Baró (1988) propone un análisis psicosocial observando los factores sociales para comprender más adecuadamente el ser y el quehacer de personas y grupo. Reafirmando esta noción, Marx (citado en Martín-Baró, 1988) asevera: "la esencia humana no es una abstracción inherente al individuo aislado. En su realidad es el conjunto de las relaciones sociales".

Maritza Montero (2004) realiza un cuestionamiento a la noción de paradigma científico que se influencia por las concepciones éticas y políticas. Ella nos propone pasar de una noción del sujeto individual que conoce, a una noción de "actores sociales". Esto implica una visión de los seres humanos que actúan y reflexionan desde la propia realidad que construyen, a partir de los discursos y de las acciones.

La concepción ética refiere a la concepción del Otro y su inclusión en producción de conocimientos. Según Dussel (1998), la dimensión ética tiene como objetivo principal la relación con el Otro en términos de 
igualdad y respeto, incluyendo la responsabilidad que cada uno tiene respecto del Otro, entendiendo por responsabilidad no el responder a, sino el responder por el Otro (Montero, 2004).

El ámbito político refiere a las cuestiones del poder, de cómo la ciudadanía tiene espacios para dialogar y participar en la toma de decisiones y de sus posibilidades de poder incidir en los asuntos de la educación. Vemos que muchas de las decisiones que se aplican al ámbito educativo, se elaboran sin considerar las necesidades sentidas de los actores sociales que constituyen la institución educativa.

Estas cuestiones son expresadas con bastante preocupación por un grupo de estudiantes de psicología social que nos anticipan cuestiones centrales y muy profundas a considerar ${ }^{5}$. En cuanto al entendimiento de la educación, la Universidad, su función y los procesos de reflexión, los estudiantes señalan:

"Educación es una experiencia que te va transformando, que te ayuda a entender tu realidad y tu contexto (...), la educación debería ser liberadora, lo que hace es funcionalizar al sujeto. (...). La educación superior quiere crear técnicos, ya no es una cuestión académica, del amor al conocimiento o la filosofía, sino de formar técnicos para crear mano de obra barata(...), de lo que le conviene a la institución (...). La universidad ha dejado de ser un ente creador de conocimientos, simplemente es un reproductor de saberes. O sea, Freud dijo tal cosa, y lo que dijo Freud se vuelve casi dogmático, no está el apoyo a los estudiantes para poder crear el conocimiento, sino simplemente reproductores del mismo... o sea están haciendo máquinas de grabar que ponen play y se repite lo mismo. (...). La universidad tiene que ser generadora de un proyecto políti- 
co, que nosotros seamos activos con lo que le pasa al país (...) todos estamos trabajando con personas que hay que mirarlas como actores sociales (...). La concepción de la verdad del estudiante tiene que ver con traer nuestra realidad acá y ahí discutir. (...). Cualquier forma de educación implica la imposición de una tesis (...). La reflexión es una forma de interrelacionar distintos elementos, espacios, experiencias, saberes, conocimientos, prácticas, de relacionar y pensar sobre eso y ver qué alternativas y formas de ver la realidad. No de imponer una solución como "La solución", relacionar y ver qué nos sirve en ese momento, y después eso mismo volverlo a pensar y ver qué alcances y problemas, y volver a reflexionar (...). La educación es para el control, las instituciones, o sea imponen la existencia de ciertas realidades, crea herramientas, el dispositivo y el robot. (...). La educación está en crisis pero no la estructura misma, que este mal, te permite el funcionamiento de crear individuos que no reflexionen, esa es la pantalla fantasmática (...). El estudiante ha dejado de ser un trabajador, ya no genera conocimientos. Simplemente se transforma en un cliente y yo estoy pagando para tener el título, fui a la universidad a ganarme un título (...). Lo malo no es la crisis, sino la respuesta que estamos dando".

En nuestra cultura la invención de teorías educativas han justificado relaciones de dominación y exclusión. Estas producciones tienden a generar cierto tipo de certidumbre que naturaliza el sistema educativo y que en función de la desconfianza recurre al control. El saber "ancla", puesto que en tanto se sabe, no se reflexiona. Si uno se pregunta por los fundamentos del hacer, inmediatamente cambia el hacer y la mirada sobre la comprensión de los fenómenos educativos. La perspectiva de intersubjetividad permite situar la reflexión en el diálogo 
social y la construcción de la realidad entre los actores sociales. Si es que nos podemos imaginar una educación para la transformación, inevitablemente requerimos una apertura al mundo reflexivo, un abandono de las certidumbres para la construcción de certidumbres. Maturana (1997), en este sentido, refiere que "no podemos dejar de notar que los seres humanos somos humanos en el lenguaje, y al serlo, lo somos haciendo reflexiones sobre lo que nos sucede".

\section{Conclusiones}

1. Estamos en un proceso de país que presupone, como prioridad, un proceso de transformación de la educación como estrategia para avanzar en justicia social. El enfoque de derechos y de cambio social es el fundamento para constatar un marco legal que garantice el proceso.

2. Los datos en torno a la educación, su cobertura y calidad, son preocupantes a la hora de tener criterios de realidad para centrar la transformación, en función de lo que tenemos y lo que podemos hacer con este contexto construido principalmente desde los espacios institucionales que ostentan el poder.

3. La verdad adultocéntrica de la educación responde a un discurso que promueve y mantiene un tipo de relaciones sociales, fundadas en la idea de la transmisión de conocimientos y valores, de quienes "saben" a otros seres humanos que "debieran saber", para que respondan a las exigencias del sistema, el cual estructura y funcionaliza nuestro estar en el mundo sociocultural. Esta concepción de "sujetos sujetados" determina y limita las posibilidades de acción-reflexión y transformación de nuestras relaciones económicas, políticas, culturales y esencialmente humanas. 
4. Existe un predominio de la noción de objetividad-subjetividad heredada de la tradición filosófica positivista, en desmedro del aspecto de la filosofía de la virtud y del estar en sociedad. Esta tradición presupone un conjunto de principios centrados en un mundo cognoscible por los sujetos con independencia de nuestra experiencia. Estamos ante un determinismo racional, a partir del cual se actúa y reproduce el mundo. La reflexión refiere a la revisión de nuestros principios, que asumimos como "verdad", si es que en el contexto del país se intenciona el proceso de cambio y transformación, esta dinámica es esencial. Una vía es la discusión sobre condiciones de educabilidad para avanzar en justicia social.

5. Los aportes de la psicología se encuadran en una convivencia pluriparadigmática que, de acuerdo a las diversas tradiciones epistemológicas y ontológicas, sigue situando el análisis en la concepción binaria de sujetoobjeto. La existencia de ciertas estructuras o representaciones que están en cada uno de los individuos, es lo que más ha predominado e influenciado el quehacer educativo.

6. Los paradigmas en psicoeducación siguen su trayectoria subjetivista con la visión humanista, que se contrapone a la visión innatista de la psicología dinámica. Se supone la autorrealización de "la persona". No obstante, vemos una emergencia del constructivismo, como cuestionamiento epistémico, que introduce una visión de interacción entre sujeto-objeto (considérese que hay diversas formas de constructivismo). Este enfoque espera crear mentes creativas y descubridoras. El conocimiento se construye activamente a través del encuentro con el entorno y organiza el mundo experiencial del "sujeto". Un enfoque poco difundido es el paradig- 
ma sociocultural de Vigotsky, en donde se asevera que las funciones psicológicas superiores se construyen en las interacciones sociales, es decir, el concepto de mediación en que el sujeto reconstruye su espacio sociocultural adquiere preponderancia.

7. Como propuesta de ampliación de las cuestiones epistemológicas en el contexto educativo, encontramos los antecedentes del construccionismo social (derivado de la crítica al pensamiento moderno). Este programa metateórico sentencia que los significados surgen desde la intersubjetividad. La comprensión del mundo y de nosotros mismos no está dado por los objetos en sí mismos, sino que éstos son el producto de los intercambios entre las personas en un espacio-tiempo específico y en contextos de poder-saber. Lo que interpretamos por educación va a depender de los discursos que adquieran una connotación de convención en la realidad institucional.

8. La discusión nos lleva a procesos de reflexión y de incorporación de las significaciones de los diversos actores sociales, involucrados en la experiencia educativa. Cabe destacar que el sujeto es producto de la capacidad reflexiva interindividual. Cada uno de nosotros se constituye en un intersujeto, rompiéndose, así, la disyuntiva sujeto/objeto. Se construye, en consecuencia, una relación circular, apelando a la construcción social de ese ser en el mundo, en donde la comprensión de los sujetos se busca en el contexto relacional.

9. Los procesos de transformación requerirán cuestionar las certezas con las cuales operamos. Las cuestiones de la existencia y del conocer adquieren relevancia como fundamentos de nuestras relaciones sociales, pero que no deben estar desvinculadas de los componentes éticos, políticos e históricos, que se significan entre nosotros y determinan nuestros intercambios humanos. 
10.La emoción adquiere también un rol fundamental, puesto que mientras no valoremos al Otro como legítimo en nuestra convivencia, seguiremos viviendo las dinámicas propias de una cultura patriarcal, en donde se naturaliza la exclusión, el dominio y el control social.

11. En consecuencia, Paulo Freire nos recalca que no es posible encarar la educación a no ser como un quehacer humano. Quehacer, por tanto, que se da en el tiempo y en el espacio, entre los hombres, unos con otros. Su vocación ontológica, que él debe existenciar, es la de sujeto que opera y transforma el mundo.

\section{Notas}

1 En este marco contamos con los aportes de Karl Popper con su enfoque falsacionista y aproximación de verosimilitud a la realidad y centrado en la elaboración de nuevas hipótesis y experimentos que tiendan a explicar los errores de teorías anteriores. También se cuenta con el programa de Imre Lakatos, quien va más allá de Popper, en el sentido de la falsación de programas por la emergencia de otros programas alternativos que resuelvan las dificultades explicativas.

2 La crisis de los fundamentos ontológicos y epistemológicos del pensamiento moderno se viene desarrollando desde la década de los sesenta, en todas las ciencias sociales. En nuestro ámbito, a esto se le llama la crisis de la psicología social. En esta crisis, según Sandoval (2002), se cuestiona y reflexiona sobre: "la capacidad del lenguaje para vehiculizar los contenidos mentales, la incredulidad sobre el hecho de que la mente contenga representaciones que realmente reflejen lo que es el mundo, la crítica al sentido progresivo y acumulativo del pensamiento científico y el cuestionamiento radical a la noción moderna de la verdad".

3 El nacimiento del socioconstruccionismo como programa psicosociológico está ligado a la figura del autor norteamericano Kenneth J. Gergen, quien en 1985 publicó, en American Psychologist, un artículo en el cual postulaba el nacimiento de un nuevo movi- 
miento teórico al interior de la psicología social (Gergen, 1985). Este programa se centra en la naturaleza social del conocimiento y el origen simbólico de la realidad.

4 Importantes han sido los aportes desde la psicología social al campo de la educación. Los programas de investigación han generando constructos explicativos y descriptivos tales como, la teoría del rol, el rol de maestro y los conflictos de roles, el rol del alumno, actitudes personales y rendimientos en los estudios, motivación y rendimiento, liderazgo, expectativas interpersonales y rendimiento en los estudios, cooperación, competencia y resolución de conflictos, entre otros. Para quien se interese en profundizar estos aspectos, remítase a revisar el libro Psicología Social de la Educación, de David Johnson.

5 La idea de realizar un grupo focal, dialogado con 7 estudiantes de la Carrera de Psicología, mención Psicología Social (UPS-Q), no fue con la intención de realizar un análisis de los contenidos de los discursos de los jóvenes, sino más bien, de contar con algunas significaciones que permitan situar la necesidad de construcción intersubjetiva. De todos modos, se evidencia una necesidad de genera espacios de diálogo en el ámbito de nuestra "realidad" institucional, para apuntar hacia procesos de reflexión-acción, en el sentido de formarnos como actores sociales para la articulación de nuevas formas de co-pertenencia y no de independencia de saberes funcionales al poder. Se podría pensar en profundizar estos espacios de diálogo, a través de investigaciones para construir nuevas relaciones-realidades situadas en las necesidades de los actores que las interpretan.

\section{Bibliografía}

FERNÁNDEZ, Pablo:

1994 Psicología Social, Intersubjetividad y Psicología Colectiva. En Montero, Maritza: Construcción y Crítica de la Psicología Social. Barcelona: Antrophos.

FREIRE, Paulo:

1973 Educación Liberadora. Madrid: editorial Zero S.A. GERGEN, Kenneth:

1996 La Crisis de la Representación y la Emergencia de la Construcción Social. En Gergen, K.; Realidades y Relaciones, Madrid: Universitas. 
GIANNINI, Humberto:

1981 Esbozo para una Historia de la Filosofía. Santiago de Chile: Vera y Giannini.

HERNÁNDEZ, Gerardo:

1998 Paradigmas en Psicología de la Educación. México: Paidós.

JOHNSON, David:

1972 Psicología Social de la Educación. Buenos Aires: Kapelusz.

MARTÍN-BARÓ, Ignacio:

1988 Acción e Ideología. San Salvador: UCA Editores.

MATURANA, Humberto:

1997 Emociones y lenguaje Educación y Política. Bogotá: Dolmen y Tm Ediciones.

MONTERO, Maritza:

2004 Introducción a la Psicología Comunitaria, Desarrollo, Conceptos y Procesos. Buenos Aires: Paidós.

SABUCEDO, J.M.:

1997 Fundamentos de Psicología Social. Madrid: Siglo XXI.

SANDOVAL, Juan:

2002 Representación, Discursividad y Acción Situada, Introducción Crítica a la Psicología Social del Conocimiento (copia electrónica).

\section{Bibliografía de Internet}

MARTÍNEZ, Enrique.

La Filosofía de la Educación como Saber Filosófico.

http//www.hottopos.com//mirand13/enrique.htm. 4 de marzo de 2009.

SANTIAGO, Lourdes.

Educación y Pedagogía. www.correodelmaestro.com/ anteriores/1997/junio/sentidos13.htm. Junio 1997. 